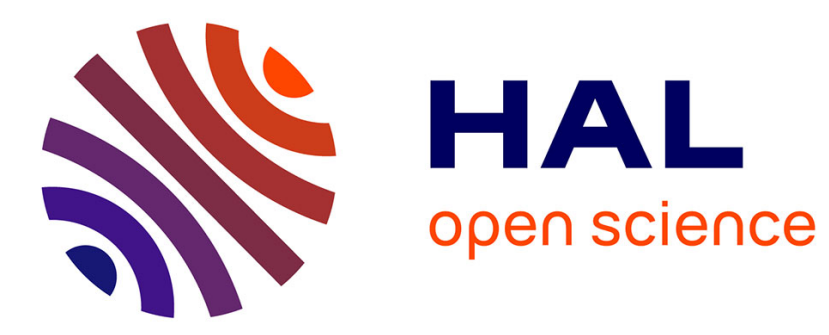

\title{
Predicting the Effects of Common Levels of Variability on Flow Processing Systems
}

David Stockton, Riham Khalil, John Anthony Fresco

\section{To cite this version:}

David Stockton, Riham Khalil, John Anthony Fresco. Predicting the Effects of Common Levels of Variability on Flow Processing Systems. International Journal of Computer Integrated Manufacturing, 2008, 21 (03), pp.325-336. 10.1080/09511920701233472 . hal-00513391

\section{HAL Id: hal-00513391 https://hal.science/hal-00513391}

Submitted on 1 Sep 2010

HAL is a multi-disciplinary open access archive for the deposit and dissemination of scientific research documents, whether they are published or not. The documents may come from teaching and research institutions in France or abroad, or from public or private research centers.
L'archive ouverte pluridisciplinaire HAL, est destinée au dépôt et à la diffusion de documents scientifiques de niveau recherche, publiés ou non, émanant des établissements d'enseignement et de recherche français ou étrangers, des laboratoires publics ou privés. 


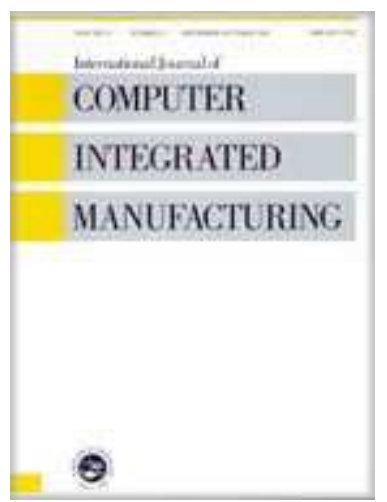

\section{Predicting the Effects of Common Levels of Variability on Flow Processing Systems}

\begin{tabular}{|r|l|}
\hline Journal: & International Journal of Computer Integrated Manufacturing \\
\hline Manuscript ID: & TCIM-2006-IJCIM-0116.R1 \\
\hline Manuscript Type: & Original Manuscript \\
\hline Author: & 11 -Jan-2007 \\
\hline & $\begin{array}{l}\text { Complete List of Authors: } \\
\text { Khalited, Rinam; Faculty of Computing Sciences \& Engineering, } \\
\text { Engineering \& Technology } \\
\text { Fresco, John; Faculty of Computing Sciences \& Engineering, } \\
\text { Engineering \& Technology }\end{array}$ \\
\hline Keywords: & $\begin{array}{l}\text { FLOW LINES, FLOW PROCESS, DISCRETE EVENT SIMULATION, } \\
\text { SYNCHRONOUS MANUFACTURING, PROBABILISTIC MODELS, } \\
\text { QUANTITATIVE MODELS }\end{array}$ \\
\hline Keywords (user): & Cycle Time Variability \\
\hline &
\end{tabular}

\section{S ScholaroNE" \\ Manuscript Central}




\title{
Predicting the Effects of Common Levels of Variability on Flow Processing Systems
}

\author{
Riham A. Khalil MBA, PhD \\ r.khalil@dmu.ac.uk \\ David John Stockton B.Sc. (Hons), M.Sc., Ph.D., M.I.E.E., C.Eng. \\ stockton@dmu.ac.uk \\ John A. Fresco, BEng. \\ De Montfort University \\ Department of Mechanical and Manufacturing Engineering \\ The Gateway, Leicester, UK. LE1 9BH. \\ Tel: +44(0) 1162551551 Ext. 8091 \\ Fax: $+44(0) 1162577052$
}

\begin{abstract}
The implementation of flow processing is essential to the successful application of lean manufacturing practices since it provides the infrastructure for both pull production to take place and the focussed elimination of waste. With the adoption of lean practices into a broader range of production environments there is an increasing need for flow processing to operate under a wider range of conditions particularly with respect to the sources and levels of variability that exist.
\end{abstract}

In order to ensure efficient flow processing under such conditions a range of methods has been developed for both reducing levels of variability and for managing the effects 
of variability. However, ensuring the effective use of each of these methods requires detailed knowledge of the effects this variability has on the resource requirements of individual workstations.

The paper presents a methodology for developing predictive models that can be used to quantitatively estimate the levels of blocking and waiting that occur on individual workstations along a flow processing line. The methodology presented makes use of discrete event simulation to generate data from which estimating models are derived that relate \%Blocking and \%Waiting arising at individual workstations with the Coefficient of Variation of their job cycle time distributions.

Key Words: Flow Lines, Flow Process, Discrete Event Simulation, Synchronous Manufacture, Probabilistic Models, Cycle Time Variability

\section{Introduction}

The basic process steps involved in the implementation of lean production (Womack, Jones and Roos, 1990, Hague and Moore, 2004) involve listening to the voice of the customer, mapping the value stream, implementing flow processing, implementing pull material control and seeking perfection through continuous improvement. Since the use of flow processing is a key element to the success of lean production its use has primarily been restricted to high volume/low product variety production environments such as typically found in automotive assembly where flow processing is relatively easy to implement. 
However, such is the success of lean practices that low demand volume/ high product variety (LDV/HPV) industrial sectors are introducing such practices within their traditional high variability manufacturing environments. A major barrier to such introductions is the limitations of traditional flow processing systems which are unable to efficiently operate with large amounts of product, process and/or demand variability. Such systems are designed to cope efficiently only within the conditions for which they were initially designed, i.e. stable demand, high and limited range in production volumes, limited variability in product designs, limited range of processes, limited range of tooling, short change-over times, limited process route options, continuous production and single products or a limited range of products that are similar in design (Yusuf and Adeleye, 2002).

Cellular manufacturing is the primary method by which flow processing has been introduced into high product variety/low demand volume manufacturing environments. However, the success of this methodology is based on the application of methods for reducing the levels of variation individual manufacturing cells need to cope with. In addition, traditional methods of designing such systems are found to rely on the assumption that task times are deterministic not stochastic.

A number of strategies have emerged for dealing with the effects of variability within manufacturing operations (Katayama and Bennett, 1996, Stalk and Hout, 1992, Imai, 1986) i.e.:

a. through the effective allocation of tasks to workstations during the line balancing procedure, 
b. effective sequencing of work items onto the flow line,

c. adoption of an optimum mechanism for controlling material flows,

d. removing the causes of variation, e.g. through set-up reduction and total quality management activities,

e. reducing the levels of variation from individual causes, e.g. through lean-based waste reduction techniques,

f. combining sources of variation, i.e. through variability pooling and buffering, and

g. making use of flexible resources to off-set the effects of variability.

Ensuring effective use of such techniques requires greater knowledge of the levels of time variability inherent in individual work tasks and workstations and the effects that differences in workstation variability have on the resource utilisations of individual workstations. Methods by which the above knowledge may be generated have, therefore, been examined in terms of quantitatively measuring the levels of blocking and waiting that arise within individual workstations as a result of variability. 'Blocking' occurs when an upstream workstation has completed its current job but cannot move the completed item to the next workstation because this next workstation is not yet ready to receive it. The upstream workstation, therefore, becomes idle since it cannot receive its next job. 'Waiting' occurs when a workstation has completed its current job and moved this on to the next workstation and is now idle whilst awaiting the arrival of its next job. The essential question to answer is how differences in the levels of variability between workstations affect the levels of blocking and waiting experienced by individual workstations along the flow line.

\section{Measuring the Effects of Variability}


A number of researchers have examined the effects of variability on the efficiency of flow lines. Much of this research has been restricted to optimising specific characteristics of flow lines or developing general rules by which flow lines may be designed. For example, Anderson and Moodie (1969) developed models for determining the optimum buffer sizes within workstations and more recently Taylor and Heragu (1999) simulated flow lines with a range of buffering strategies and cycle times that possessed a variety of means and variances. They found that work-in-progress and cycle time improvement resulted from reductions in the mean and variance of workstation job times. The level of improvement varied greatly depending on the type of distribution being investigated.

Carnall and Wild (1976) determined the effect on output efficiency and average idle time of buffer capacity, service time variability and the order of placement of constant work time and variable work time stations along a flow line. This latter characteristic has been of interest to a number of researchers with El Rayah (1979) carrying out computer simulation experiments to determine whether deliberate unbalancing of flow lines improved the output rate of a line. This work confirmed the existence of the bowl phenomena (Hillier and Boling 1967). The practical application of the bowl phenomenon appears to provide a method of increasing the throughput of flow processing lines with variable processing times by purposely unbalancing the line in a certain manner (Hillier and Boling 1967). In this respect Hillier and So (1993) have shown that the 'bowl' phenomenon can be applied to the optimal allocation of work for somewhat larger flow processing lines than previously considered by Hillier and Boling (1967). 
In terms of developing quantitative models for measuring the effects of variation within flow lines an early attempt was that of Hunt (1956) who developed queueing models for two-workstation flow lines capable of determining the maximum possible utilisation of a line and the mean number of units in the system. Attempts to derive models applicable to production lines with greater numbers of work stations by Freeman (1968) focused on deriving empirical models for determining the overall utilisation of such lines. This work used the output data from simulation experiments to developing regression based models.

A model for estimating flow line throughput was developed by Muth and Alkaff (1987) for general values of mean processing time, coefficient of variation of these processing times and number of workstations within the flow line. This model was based on earlier work (Muth 1977) that used a combination of theoretical analyses and numerical curvefitting in its construction but was limited to production lines with zero buffer quantities between workstations. In order to overcome these zero buffer size restrictions Blumenfeld (1990) developed an extension of Muth and Alkaff's (1987) model using the model developed by Hunt (1956) to provide the analytical form of this extension. Close agreement was found when compared with results from studies by Hillier and Boling (1967) and Freeman (1968).

The approach adopted by Hopp and Spearman (2000) to account for variability within a flow line involved the determination of an 'effective cycle time' for each workstation. Their method used a measure of workstation availability, (ie the proportion of time the 
workstation is available to process components as a result of stoppages caused by such activities as changeovers, equipment breakdowns and planned maintenance), to modify the workstation cycle time. As breakdowns, planned maintenance and changeover times and/or frequencies increased then the effective time required for a workstation to complete its allocated work also increased. The work of Hopp and Spearman (2000) was constrained to developing single values for workstation effective cycle times. This was later extended by Khalil (2004) to include the three values that define the limits of a triangular distribution, ie shortest, most likely and longest effective times.

\section{Development of Variability Estimating Models}

The current work extends that undertaken by Hopp and Spearman (2000) and Khalil (2004) by determining the levels of blocking and waiting arising on flow lines as a result of the variability in these effective cycle times. Workstation cycle time variability distributions were categorised as illustrated in Figure 1 according to the values of their shortest (A), longest (B) and most likely (T) times with these times ranging from 0 to 6 time units.

\section{Figure 1: Categories of Probability Distributions}

Simulation models of flow lines of $2,3,5,8,13$ and 21 workstations in length were developed using a discrete event simulation package (Hauge and Paige, 2001). These models were used to identify the effects of increasing levels of workstation cycle time on the basic manner in which the \%Blocking and \%Waiting of individual workstations varied along a flow line. 
Simulation trials were undertaken for each flow line model in which each trial consisted of 50 individual simulation runs. Each simulation run was performed using a unique pseudo random number set that was mathematically generated by the simulation package. The values of $\%$ Blocking and \%Waiting arising from these simulation trials were then used to derive $\%$ Blocking and \%Waiting estimating equations.

The results used to develop the estimating equations represented the average value of $\%$ Blocking and \%Waiting obtained from each trial. In order to measure the reliability of these average values, for each trial its Standard Deviation of Averages was calculated, ie Standard Deviation of Results divided by the square root of the Number of Runs per trial. These results indicated that for all simulation trials, there was less then $1 \%$ difference between average values and their $99.9 \%$ confidence interval values.

Using the results of 2 workstation flow lines Correlation Coefficients were used to compare the work station \%Blocking and \%Waiting levels arising from the simulation trials with variability means, geometric means, harmonic means, PERT means, standard deviations, coefficient of variations and the medians of the work station cycle time variabilities, i.e. Table 1. A correlation matrix for these statistical characteristics in provided in Table 2 and shows that in general there is a low level of correlation between them with perfect positive correlation existing between 1 pair of characteristics, strong positive and negative correlations between 4 pairs of characteristics and medium to zero positive and negative correlations between 15 pairs of characteristics. Overall, therefore, the statistical characteristics are orthogonal. Figure 2 provides a plot of 
$\%$ Blocking/\% Waiting versus Coefficient of Variation and illustrates that these latter values satisfy the requirements for a valid correlation analysis, ie the values are approximately normally distributed and there is no single value that is greatly separated from the rest of the values.

Table 1: Correlation Coefficient Values for Statistical measures with \% Blocking \& \% Waiting on 2 Workstation Flow Lines

Table 2: Correlation Matrix for Statistical Characteristics

Figure 2: \% Blocking/\% Waiting vs Correlation Coefficient Values

It can be seen that of the statistical measures listed in Table 1 the Coefficient of Variation possesses the greatest level of correlation. The data provided by the simulation results were then used to develop estimating equations for using the 
Coefficient of Variation to calculate \%Blocking and \%Waiting arising from a specific variability category, i.e. Equations 1 and 2 . Here the first subscript, m, of the notation $\% \mathrm{~B}_{\mathrm{m}, \mathrm{n}}$ identifies the position of the workstation along the flow line and the second subscript, $\mathrm{n}$, identifies the number of workstations in the flow line. Hence, $\% \mathrm{~B}_{1,2}$ represents the $\%$ blocking of the first workstation in a two-workstation line.

$$
\% \mathrm{~B}_{1,2}=1.37+\left(40.33 \cdot \mathrm{CV}_{1,2}\right)
$$

Where:

$\% \mathrm{~B}_{1,2}=\%$ Blocking on the $1^{\text {st }}$ Workstation of a 2-workstation flow line.

$\mathrm{CV}_{1,2}=$ Coefficient of variation of the $1^{\text {st }}$ Workstation of a 2-workstation flow line.

$$
\% \mathrm{~W}_{2,2}=0.98+\left(44.51 \cdot \mathrm{CV}_{1,2}\right)
$$

Where:

$\% \mathrm{~W}_{2,2}=\%$ Waiting on the $2^{\text {nd }}$ Workstation of a 2-workstation flow line

The maximum positive and negative differences between simulation and estimated values were used to determine estimating accuracy, i.e. differences ranged between $0.51 \%$ and $+0.53 \%$ for Equation 1 and $-0.46 \%$ and $+0.38 \%$ for Equation 2 . Figure 3 illustrates the level of agreement achieved between estimated and simulation values for both blocking and waiting when using these models. In this figure the workstation variability is represented by the three values that define the triangular probability 
distribution, eg 036 represents a shortest possible time of 0 , most likely time of 3 and a longest possible time of 6 time units.

\section{Figure 3: Comparison of Estimated vs. Simulated \%Blocking \& \% Waiting on 2 Workstation (WS) Flow Lines}

Simulation trials were then undertaken to identify the relationships between $\%$ Blocking and \%Waiting of the 'number of workstations within a flow line' and the 'position of an individual workstation along the line'. Here trials involved simulating flow lines of varying lengths $2,3,5,8,13$ and 21 workstations for each of the variability categories shown in Figure 1. From these trials values for both the $\%$ Blocking and \%Waiting arising at each workstation along the line were obtained.

Examination of the outputs from simulation models enabled the basic manner in which $\%$ Blocking and \% Waiting of individual workstations varied along a flow line to be identified in Figures 4 to 9.

Figure 4: \% Blocking and \% Waiting on 2 Workstation Flow Lines

Figure 5: \% Blocking and \% Waiting on 3 Workstation Flow Lines 
Figure 6: \% Blocking and \% Waiting on 5 Workstation Flow Lines

Figure 7: \% Blocking and \% Waiting on 8 Workstation Flow Lines

Figure 8: \% Blocking and \% Waiting on 13 Workstation Flow Lines

Figure 9: \% Blocking and \% Waiting on 21 Workstation Flow Lines

These data provided by the simulation results were used to develop estimating equations for using the number of workstations within a flow line and the position of a workstation within a flow line to calculate \%Blocking arising at an individual workstation as follows:

Models were developed for estimating $\% \mathrm{~B}_{1, \mathrm{n}}$, i.e. the $\%$ Blocking on the first workstation of a multi-workstation flow line. Here the following models were developed for flow lines with a minimum number of workstations of 3 , ie the minimum value of $n=3$. 


$$
\begin{aligned}
& \mathrm{C}_{1, \mathrm{n}}=2.19+(0.07 . \mathrm{n}) \\
& \mathrm{Cf}_{1, \mathrm{n}}=1.45+(0.01 . \mathrm{n}) \\
& \% \mathrm{~B}_{1, \mathrm{n}} \quad=\mathrm{C}_{1, \mathrm{n}}+\left(\mathrm{Cf}_{1, \mathrm{n}} \cdot \% \mathrm{~B}_{1,2}\right)
\end{aligned}
$$

Where:

$\mathrm{C}_{1, \mathrm{n}} \quad=$ Value of the constant calculated in Equation 3.

$\mathrm{Cf}_{1, \mathrm{n}} \quad=$ Value of the coefficient calculated in Equation 4.

$\% \mathrm{~B}_{1, \mathrm{n}}=\%$ Blocking of the $1^{\text {st }}$ workstation on an $\mathrm{n}$ workstation line.

$\mathrm{n} \quad=$ Number of workstations on the line.

Maximum positive and negative differences between simulation and estimated values ranged between -2.50 and +2.76 .

Models were then developed for estimating $\% \mathrm{~B}_{\mathrm{n}-1, \mathrm{n}}$, i.e. the $\%$ Blocking on the "last but one" workstation of a multi-workstation flow line. The \%Blocking of the last workstation on the line is assumed to be zero. Here the following models were developed:

$$
\begin{aligned}
& \mathrm{C}_{\mathrm{n}-1, \mathrm{n}}=0.43+(0.01 . \mathrm{n}) \\
& \mathrm{Cf}_{\mathrm{n}-1, \mathrm{n}}=0.54+(0.01 . \mathrm{n})
\end{aligned}
$$




$$
\% \mathrm{~B}_{\mathrm{n}-1, \mathrm{n}}=\mathrm{C}_{\mathrm{n}-1, \mathrm{n}}+\left(\mathrm{Cf}_{\mathrm{n}-1, \mathrm{n}} \cdot \% \mathrm{~B}_{1,2}\right)
$$

Where:

$\mathrm{C}_{\mathrm{n}-1, \mathrm{n}}=$ Value of constant calculated in Equation 6.

$\mathrm{C} \mathrm{f}_{\mathrm{n}-1, \mathrm{n}}=$ Value of coefficient calculated in Equation 7.

$\% \mathrm{~B}_{\mathrm{n}-1, \mathrm{n}}=\%$ Blocking of the $1^{\text {st }}$ workstation on an $\mathrm{n}$ workstation line.

Maximum positive and negative differences between actual and estimated values ranged between -4.42 and +3.00 .

Finally, models were developed for estimating $\% \mathrm{~B}_{2, \mathrm{n}}$, to $\% \mathrm{~B}_{\mathrm{n}-2, \mathrm{n}}$, i.e. the $\%$ Blocking on workstations 2 to $\mathrm{n}=\mathrm{n}-2$. Here the following models were developed:

$$
\mathrm{S}=\left(\% \mathrm{~B}_{1, \mathrm{n}}-\% \mathrm{~B}_{\mathrm{n}-1, \mathrm{n}}\right) /(\mathrm{n}-2)
$$

For $\mathrm{i}=2$ to $\mathrm{i}=\mathrm{n}-2$

$$
\% \mathrm{~B}_{\mathrm{i}, \mathrm{n}}=\% \mathrm{~B}_{1, \mathrm{n}}-(\mathrm{S} .(\mathrm{i}-1))
$$

Where:

$\mathrm{S} \quad=$ Rate of change of $\%$ Blocking between workstations, i.e. the slope.

$\mathrm{i}=$ Position of workstation in the line.

$\% \mathrm{~B}_{\mathrm{i}, \mathrm{n}}=\%$ Blocking of the $\mathrm{i}^{\text {th }}$ workstation of a flow line $\mathrm{n}$ workstations in length. 
Maximum positive and negative differences between simulation and estimated values ranged between -5.23 and +4.86 . Figures 10 to 13 illustrate the level of agreement achieved between estimated and simulation values using these estimation models.

For flow lines containing workstations with common levels of variability the 'sum of the \%Blocking and \%Waiting' was approximately equal at all workstations along the line". Hence, knowledge of the \%Blocking at each workstation along the line would enable the \%Waiting to be calculated at individual workstations.

Figure 10: Comparison of Estimated \& Simulated \%Blocking on 5 Workstation Flow Lines: Zero Blocking on $5^{\text {th }}$ Workstation

Figure 11: Comparison of Estimated \& Simulated \%Blocking on 8 Workstation Flow Lines: : Zero Blocking on $8^{\text {th }}$ Workstation

Figure 12: Comparison of Estimated \& Simulated \% Blocking on 3 Workstation Flow Lines : Zero Blocking on $13^{\text {th }}$ Workstation 


\section{Figure 13: Comparison of Estimated \& Simulated \%Blocking}

on 21 Workstation Flow Lines: Zero Blocking on $21^{\text {st }}$ Workstation

\section{Discussion and Conclusions}

Identifying the precise distribution type that applies in practice requires observations of work being carried out and the collection and analysis of real activity time data. Such observations can be both time and resource intensive. In addition, they are often subject to bias in the randomness of the times when observations are taken, the level of experience and motivation of the operators being observed and the standardisation of the work methods used. In addition, it is possible that each individual probability type is valid only under the particular set of conditions observed. Should these conditions change then the probability type and characteristics may become invalid. Regular checks would, therefore, need to be carried out to ensure that changes had not occurred that adversely affected the suitability of the probability distribution type being used. Choosing a distribution type, therefore, can resolve into trade-offs between the degree of accuracy required from the results and the effort required to accurately determine both the probability distribution type and values for the measures that quantitatively define the distribution, e.g. the mean and standard deviation of the normal distribution. It is primarily for this reason that the Triangular distribution has been chosen since this type of distribution easily allows a trade-off between accuracy of results and ease of estimation of the distribution parameters. 
Discrete event simulation models have been developed that can calculate the effect of differences in levels of variability between workstations on the levels of blocking and waiting experienced by individual workstations along a flow line. From examination of these results the following can be observed, i.e.:

i. The $\%$ Blocking at the $1^{\text {st }}$ workstation was approximately equal to the $\%$ Waiting at the last workstation in the line.

ii. The value of the maximum level of \%Blocking, and hence \%Waiting, is related both to the level of variability, as measured by the Coefficient of Variation, exhibited by workstations and the number of workstations within the flow line.

iii. The \%Blocking was at its maximum at the $1^{\text {st }}$ workstation and gradually decreased at each subsequent workstation until becoming zero at the last workstation. It is assumed that items can always exit instantaneously from the last workstation and hence no blocking occurs at this work area.

iv. The $\%$ Waiting was zero at the $1^{\text {st }}$ workstation and gradually increased at each subsequent workstation until reaching its maximum at the last workstation. It is assumed there is no waiting for items to be transferred to the $1^{\text {st }}$ workstation, i.e. instantaneous replenishment.

v. The sums of the \%Blocking and \%Waiting were approximately equal at all workstations along the line. 
Mathematical models, (Equations 3 and 4), have been developed for quantitatively estimating the levels of blocking and waiting arising at individual workstations as a result of the effects of workstation cycle time variability. These models are able to quantitatively estimate both \% Blocking and \%Waiting levels for individual workstations within a flow processing line. The predictive variables within these models include workstation position in the flow line, line length in terms of the number of workstations, and the levels of cycle time variability exhibited by workstations. The models developed are capable of estimating the \%Blocking and the \%Waiting levels arising on flow processing lines up to 21 workstations in length where there are common levels of variability between each workstation. The accuracy of the estimates generated by the model, when compared with results obtained from simulation experiments, are in the range -0.46 and +0.38 .

The models for estimating the levels of blocking and waiting occurring at individual workstations, would contribute to the improvement in the design and operation of flow processing lines containing high levels of variability. These improvements will arise from using knowledge of levels of blocking and waiting arising at individual workstations to enable more effective use of the available methods for dealing with the effects of variability as follows:

i. Improved use of flexible labour through using knowledge of the blocking and waiting levels arising at individual workstations to plan levels of labour flexibility required and develop suitable training matrices for providing these levels of 
flexibility. In addition improved control of the movement of labour during operation of the flow line could be gained by moving operators from an upstream workstation with high levels of waiting to a downstream workstation that possesses high levels of utilisation, by moving operators from a downstream workstation with high levels of blocking to an upstream workstation that possesses high levels of utilisation, and by avoiding the movement of operators between workstations that both possess high levels of blocking and/or waiting.

ii. Improved line balancing through use of the knowledge of blocking and waiting levels to allocate tasks to workstations such that one or more of the following objectives are achieved, i.e.: balanced levels of blocking and waiting at each workstation; causes of high levels of blocking and waiting limited to specific workstations to facilitate improvement through continuous improvement exercises and/or to simplify and improve flexible labour planning; avoidance of high levels of blocking and waiting occurring at workstations that contain 'scarce' resources hence ensuring effective utilisation of these resources.

iii. Removing causes and reducing levels of variability through focussing improvement resources and activities at those workstations that are the cause of high levels of blocking and waiting.

iv. Improved variability buffering through provision of suitable material buffers feeding workstations that have high levels of waiting, reduction of buffers feeding 
workstations with high levels of blocking, and/or providing buffers after workstations with high levels of blocking.

v. Improved sequencing of work items onto the flow line through development of appropriate production schedules for workstations causing high levels of blocking and waiting, i.e. these schedules would need to minimise levels of variability, for example by reducing the number of set-ups, and/or help to restrict the occurrence of high levels of variability to those work periods in which they can be better dealt with.

Trials were undertaken to test the relevance of the \%Blocking and \%Waiting estimating equations with respect to their use with:

1. Gaussian distributions - here flow lines with 5, 7, 9 and 21 work stations were simulated, firstly using Gaussian time distributions and then Triangular time distributions, in which the Means and Standard Deviations of each distribution type were equivalent. Results revealed that the maximum positive and negative differences between \%Blocking levels arising on workstations that possessed Guassian distributions and those that possessed Triangular distributions ranged between $-0.06 \%$ and $+2.43 \%$.

2. Work station variability levels outside the range used in their development, ie (0 to 6 time units) - here flow lines with 5, 7, 9 and 21 work stations were simulated using variability levels that ranged between 0 to 10 time units. Equations 1 to 10 were then 
used to estimate levels of blocking and waiting arising on the same flow lines. Comparisons of the simulation and estimated values revealed that the maximum positive and negative differences between simulated and estimated values ranged between $-3.17 \%$ and $+5.40 \%$.

Given the imprecise nature of the methods used to deal with the effects of variability, particularly the deployment of flexible labour, the results obtained from both trials indicated that the estimating equations developed would be valid over a wide range of variability levels as well as being applicable to probability distributions that are similar in nature to triangular distributions.

\section{References}

Anderson, D. R. and Moodie, C. L., (1969), “Optimal buffer storage capacity in production line", International Journal of Production Research, 7/3, pp 233-241.

Blumenfeld, D. E., (1990), “A simple formulae for estimating throughput of serial production lines with variable processing times and limited buffer capacity “, International Journal of Production Research, 28/6, pp 1163-1182.

Carnall, C. A. and Wild, R., (1976), "Location of variable work stations and the performance of production flow lines", International Journal of Production Research, 14/6, pp 703-710. 
El Rayah, T.E., (1979), "Effect of inequality of interstate buffer capacities and operation time variability on the efficiency of production line systems", International Journal of Production Research, 17/1, pp 77-89.

Freeman, D.R., (1968), “A general line balancing model”, Proceedings of the 19th Conference AIIE, pp 230-235.

Hague, B. and Moore, M.J., (2004), "Measures of performance for lean production in the aerospace industry", proceedings of the Institution of Mechanical engineers - Part B, Engineering Manufacture, Vol.218, Issue 10, pp 1387-1398.

Hauge, J. and Paige, K., (2001), Learning Simul8: The Complete Guide, PlainVu Publishers, Bellingham WA.

Hillier, F.S. and Boling, R.W., (1967), "Finite queues in series with Exponential or Erlang servicing times", Operations Research, Vol. 15, pp 286.

Hillier, F.S. and So, K.C., (1993), "Some data for applying the bowl phenomenon to large production line systems", International Journal of Production Research, 31/4, pp 811-822.

Hopp, J.W. and Spearman, M.L., (2000), Factory Physics: Foundations of Manufacturing Management, Irwin, Chicago. 
Hunt, G.C., (1956), "Sequential arrays of waiting times”, Operations Research, Vol.4, pp 674-678.

Imai, M., (1986), Kaizen, the key to Japan's competitive success, McGraw-Hill, New York and London.

Katayama, H. and Bennett,D., (1996), "Lean production in a changing competitive world: a Japenese perspective", International Journal of Operations and Production Management, Vol. 16, No.2., pp 8-23.

Khalil, R.A., (2004), "Predicting the effect of variation on flow processing systems", Unpublished PhD, De Montfort University, Leicester, UK.

Muth, E.J., (1977), "Numerical Methods Applicable to a Production Line with Stochastic Servers," TIMS Studies in the Management Sciences, v7, pp 143-159.

Muth, E. J. and Alkaff, A., (1987), “The throughput rate of three-station production lines: a unifying solution”, International Journal of Production Research, 25/10, pp 1405-13.

Stalk, G.and Hout, T.M., (1992), Competing Against Time, The Free Press, New York.

Taylor, G.D. and Heragu, S.S., (1999), “A comparison of mean reduction versus variance reduction in processing times in flow shops", International Journal of Production Research, 37/9, pp 1919-1934. 
Womack, J.P., Jones, D.T. and Roos, D., (1990), The machine that changed the world, Rawson Associates, New York.

Yusuf, Y.Y. and Adeleye, E.O., (2002), “ A competitive study of lean and agile manufacturing with a related survey of current practices in the UK", International Journal of Production Research, 40/17, pp 4545-4562. 


\section{TABLES}

$\begin{array}{lcc}\text { Statistical Measure } & \text { \% Blocking } & \text { \% Waiting } \\ \text { Mean } & -0.39 & -0.42 \\ \text { Geometric Mean } & -0.80 & -0.82 \\ \text { Harmonic Mean } & -0.86 & -0.87 \\ \text { PERT Mean } & -0.39 & -0.42 \\ \text { Median } & 0.05 & 0.03 \\ \text { Standard Deviation } & 0.91 & 0.90 \\ \text { Coefficient of Variation } & 1.00 & 1.00\end{array}$

Table 1: Correlation Coefficient Values for Statistical measures with \% Blocking \& \% Waiting on 2 Workstation Flow Lines 


\begin{tabular}{|l|c|c|c|c|c|c|}
\cline { 2 - 7 } & \multirow{2}{l|}{$\begin{array}{c}\text { Geometric } \\
\text { Mean }\end{array}$} & $\begin{array}{c}\text { Harmonic } \\
\text { Mean }\end{array}$ & $\begin{array}{c}\text { PERT } \\
\text { Mean }\end{array}$ & Median & $\begin{array}{c}\text { Standard } \\
\text { Deviation }\end{array}$ & $\begin{array}{c}\text { Coefficient } \\
\text { of Variation }\end{array}$ \\
\hline Mean & 0.78 & 0.75 & 1.00 & 0.79 & 0.00 & -0.42 \\
\hline Geometric Mean & & 0.99 & 0.78 & 0.39 & -0.53 & -0.83 \\
\hline Harmonic Mean & & & 0.75 & 0.34 & -0.61 & -0.88 \\
\hline PERT Mean & & & & 0.79 & 0.00 & -0.42 \\
\hline Median & & & & & 0.42 & 0.03 \\
\hline Standard Deviation & & & & & & 0.90 \\
\hline
\end{tabular}

Table 2: Correlation Matrix for Statistical Characteristics 


\section{FIGURES}
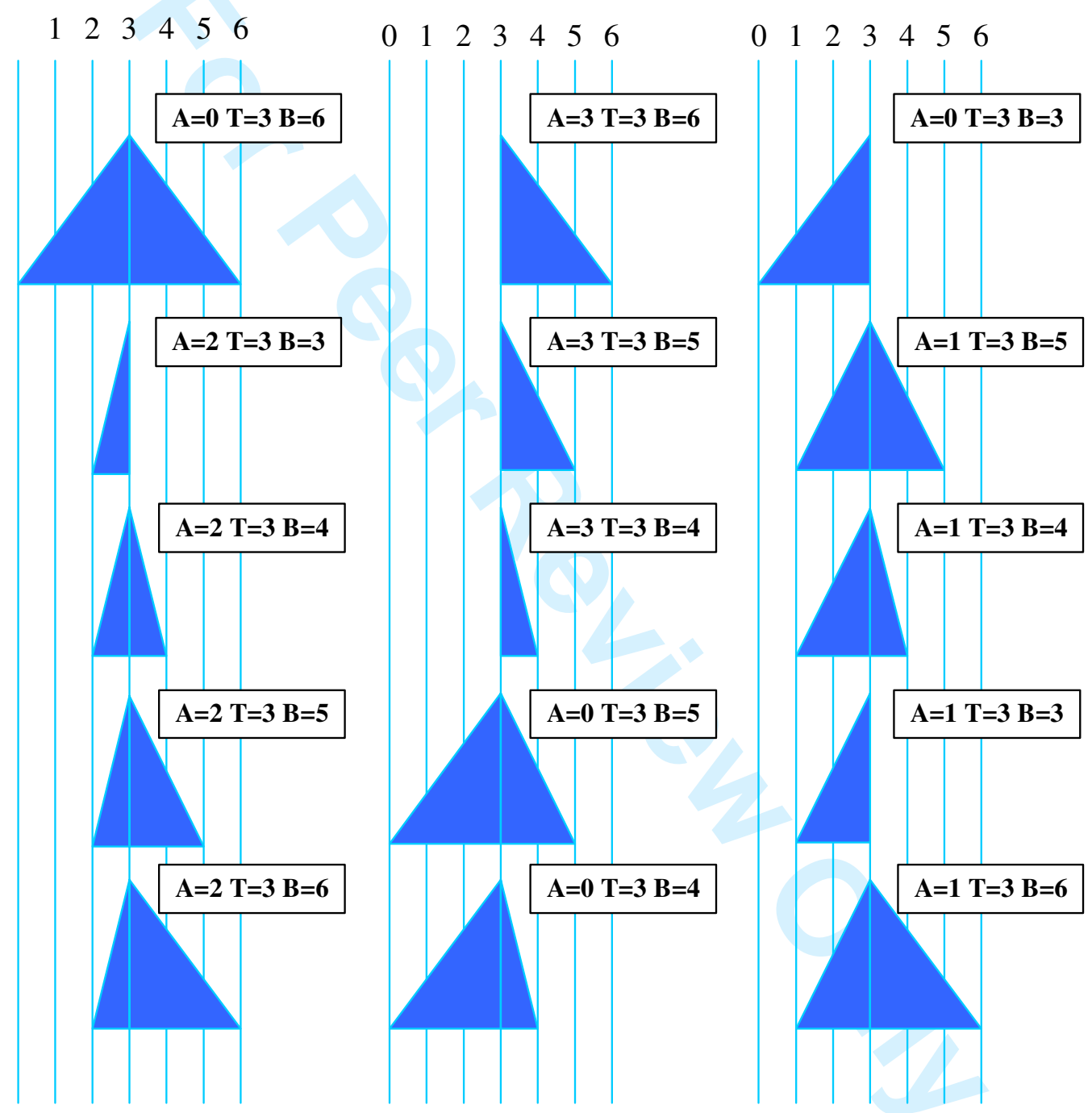

Figure 1: Categories of Probability Distributions 


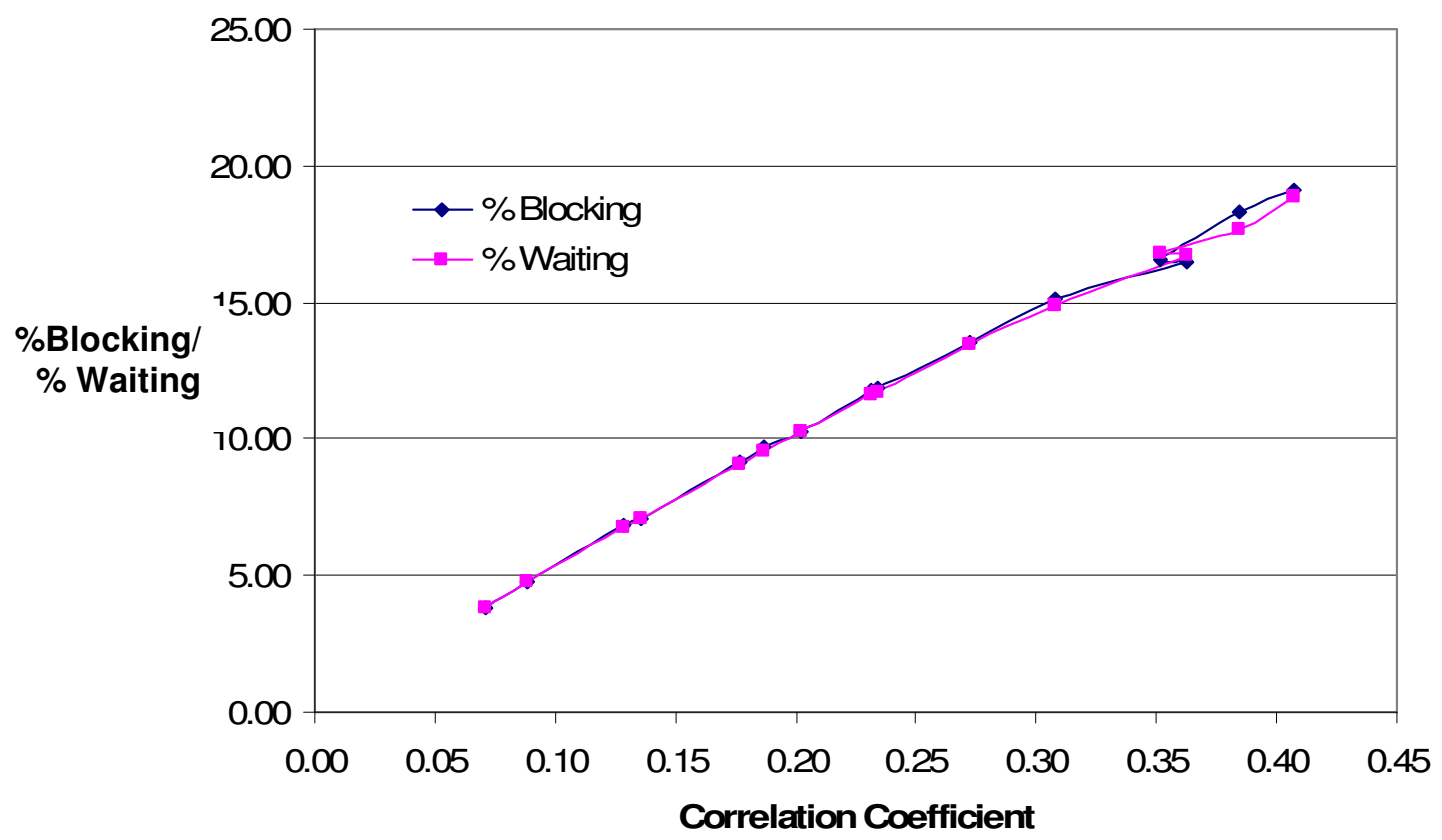

Figure 2: \% Blocking/\% Waiting versus Correlation Coefficient Values 


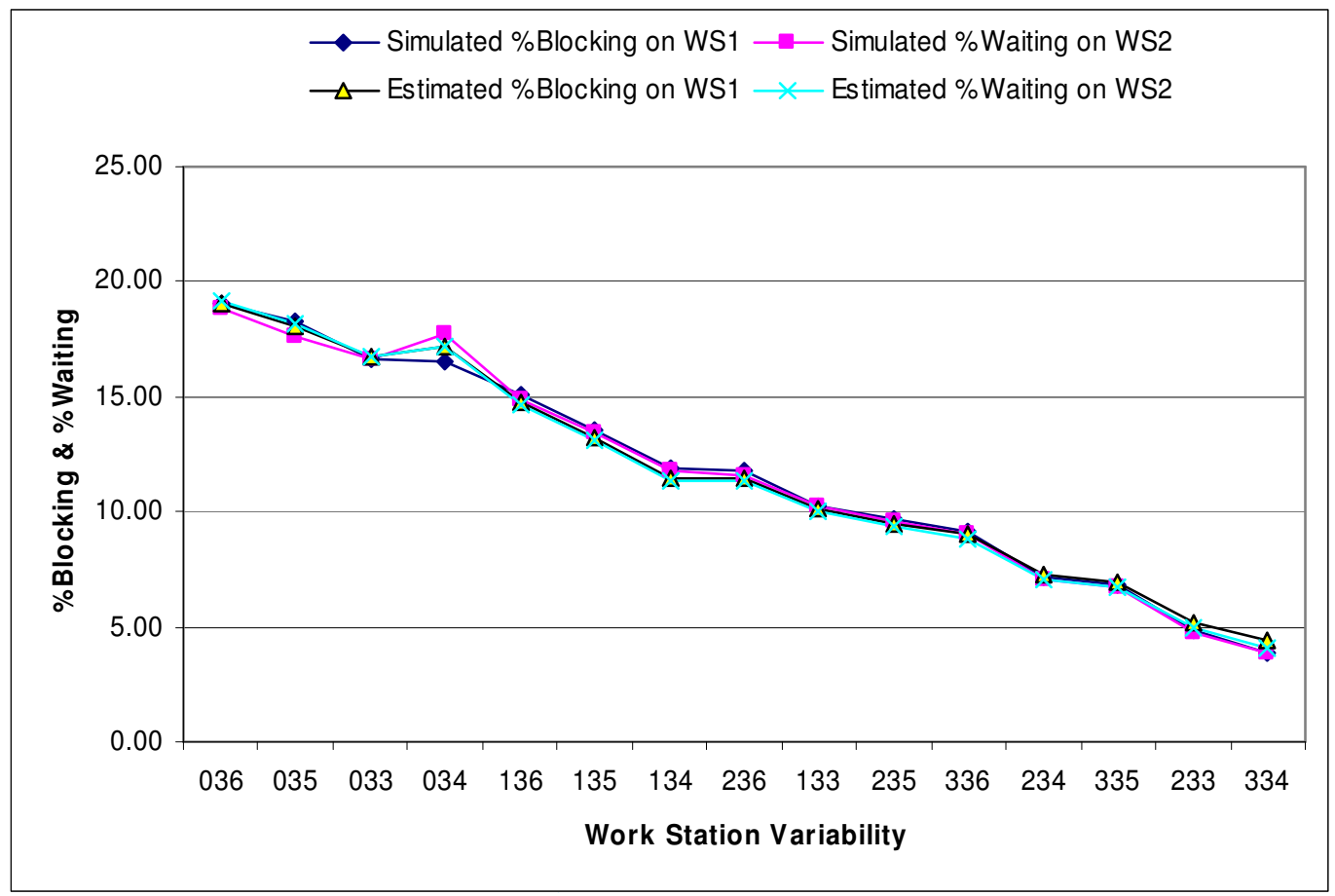

Fig

ure

3:

Co

mp

ari

son

of

Est

im

ate d vS. Si mu lat ed $\%$

Blocking \& \% Waiting on 2 Workstation (WS) Flow Lines 


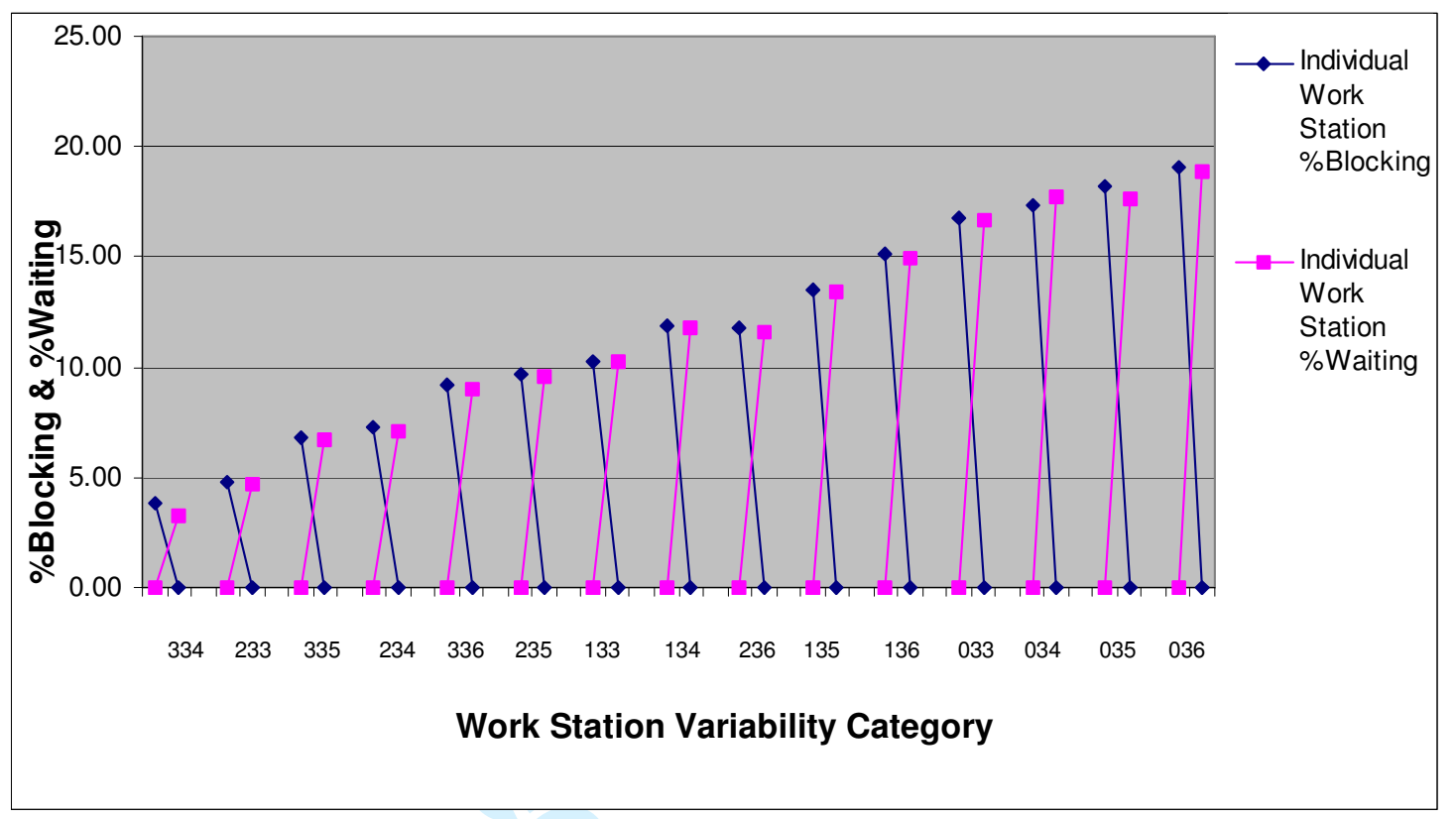

Figure 4: \% Blocking and \% Waiting on 2 Workstation Flow Lines 


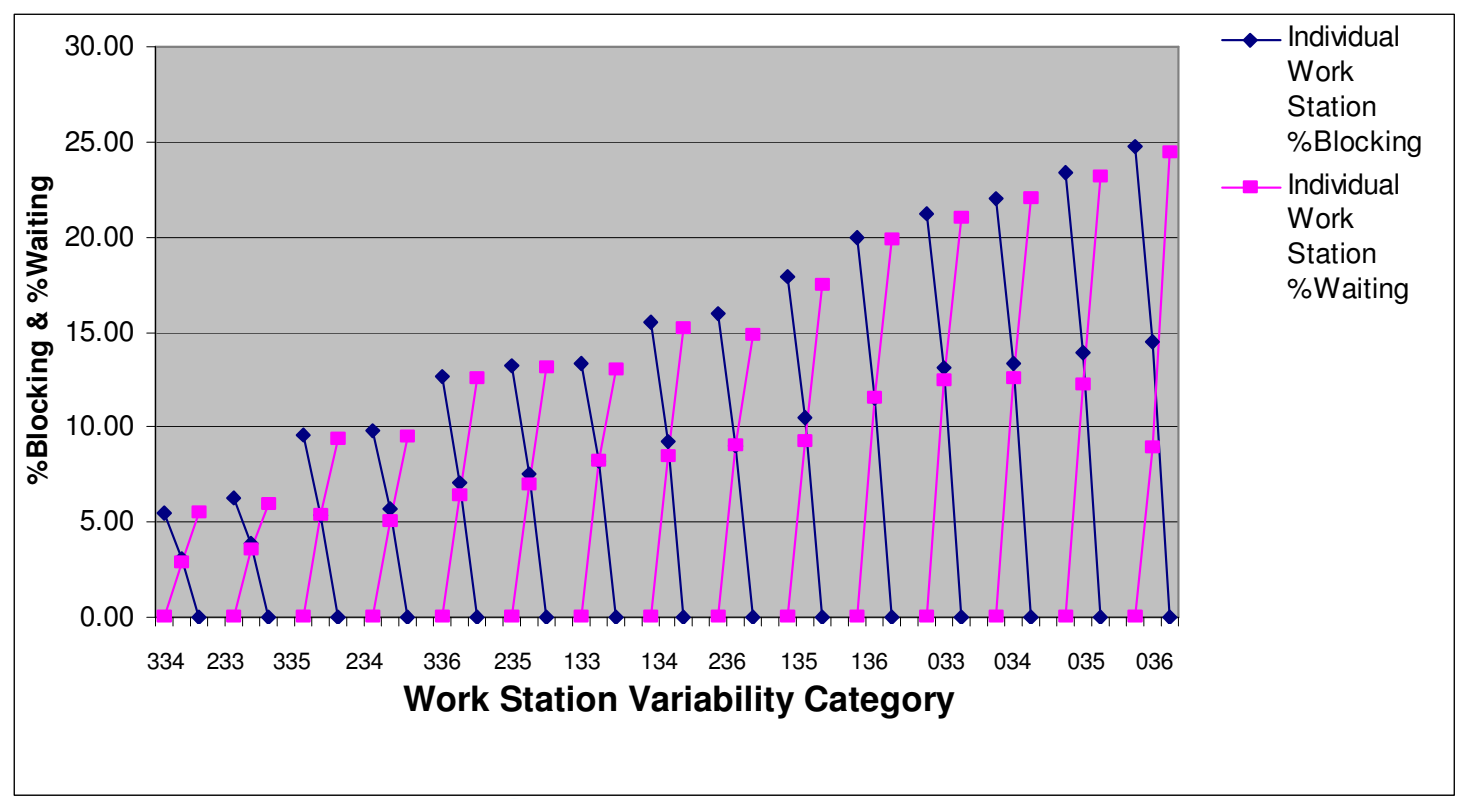

Figure 5: \% Blocking and \% Waiting on 3 Workstation Flow Lines 


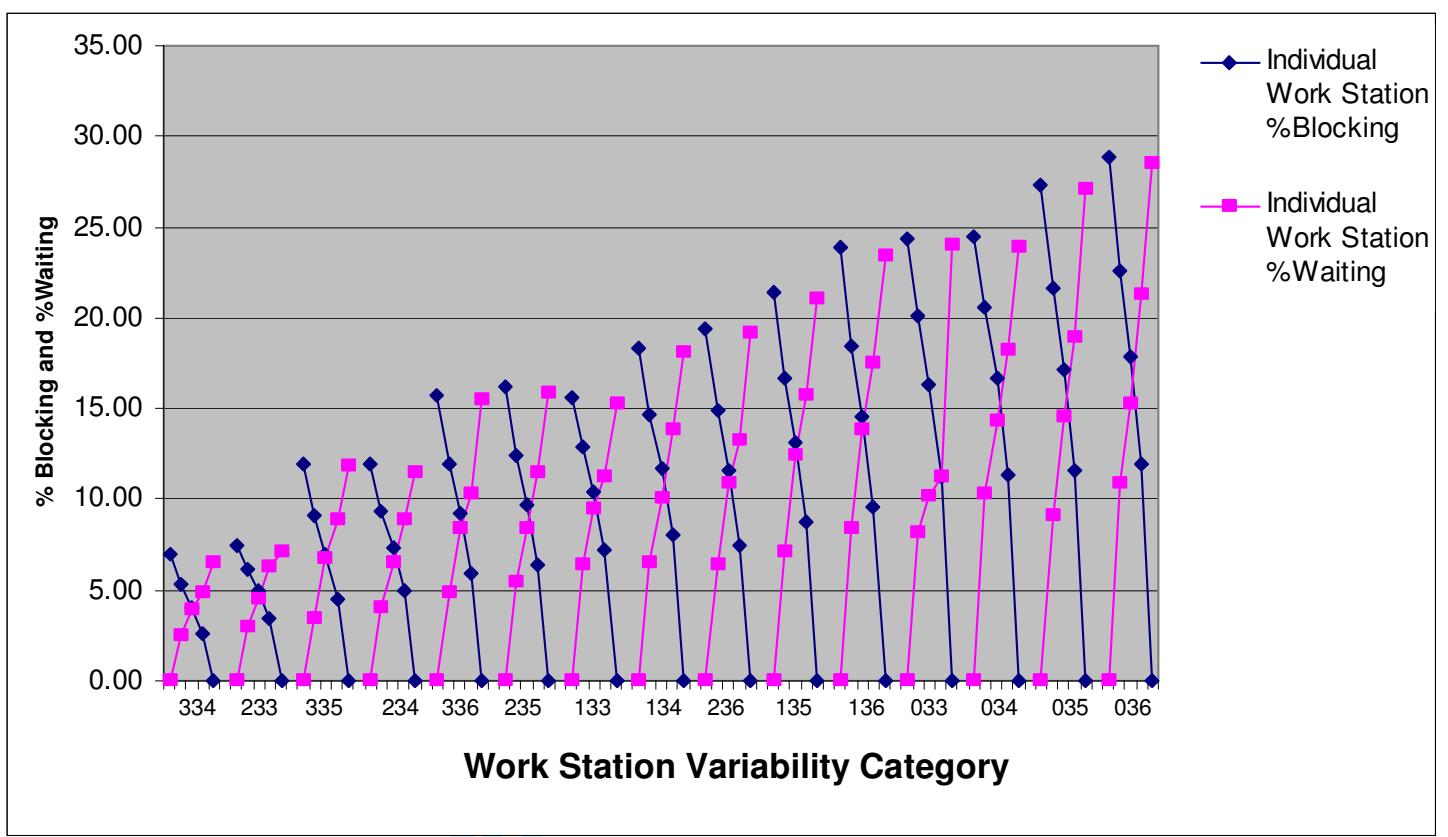

Figure 6: \% Blocking and \% Waiting on 5 Workstation Flow Lines 


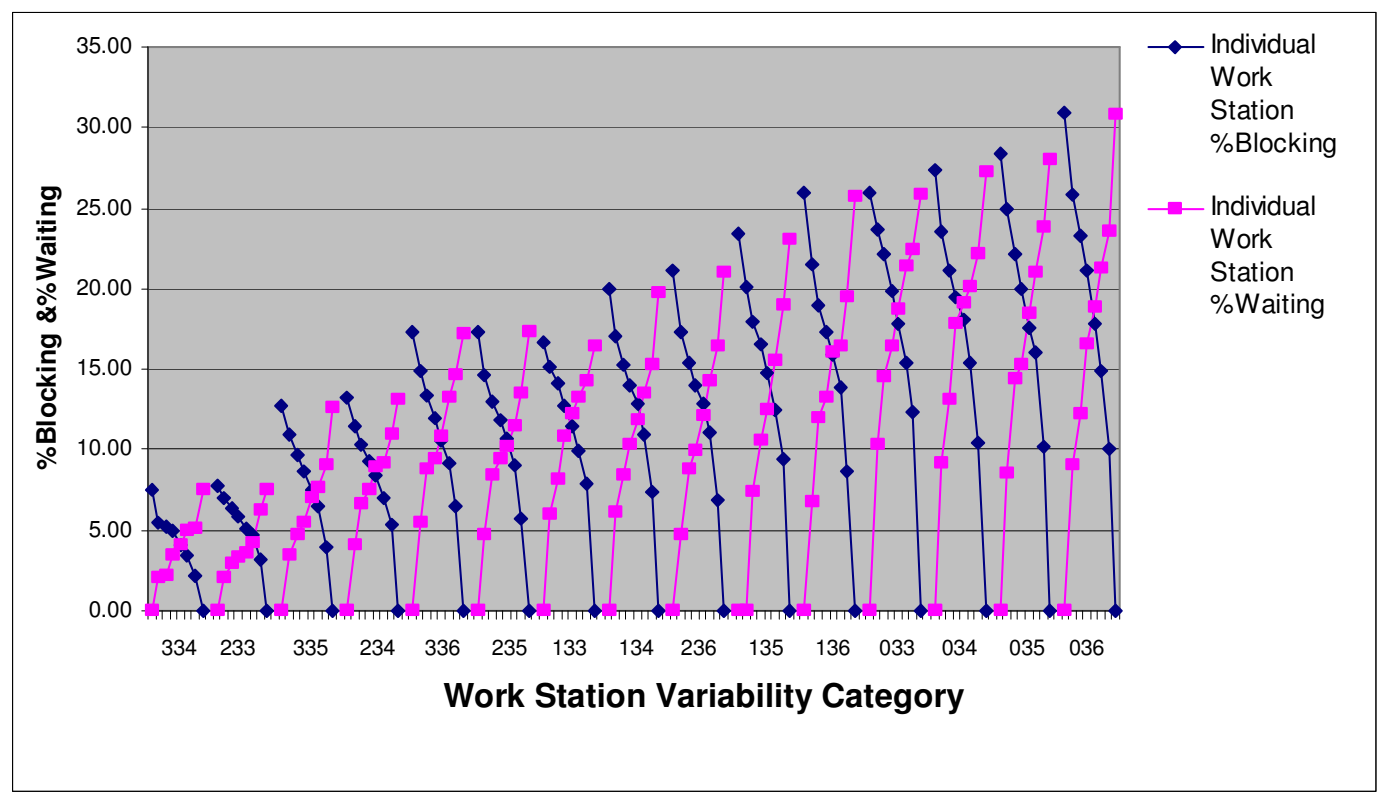

Figure 7: \% Blocking and \% Waiting on 8 Workstation Flow Lines 


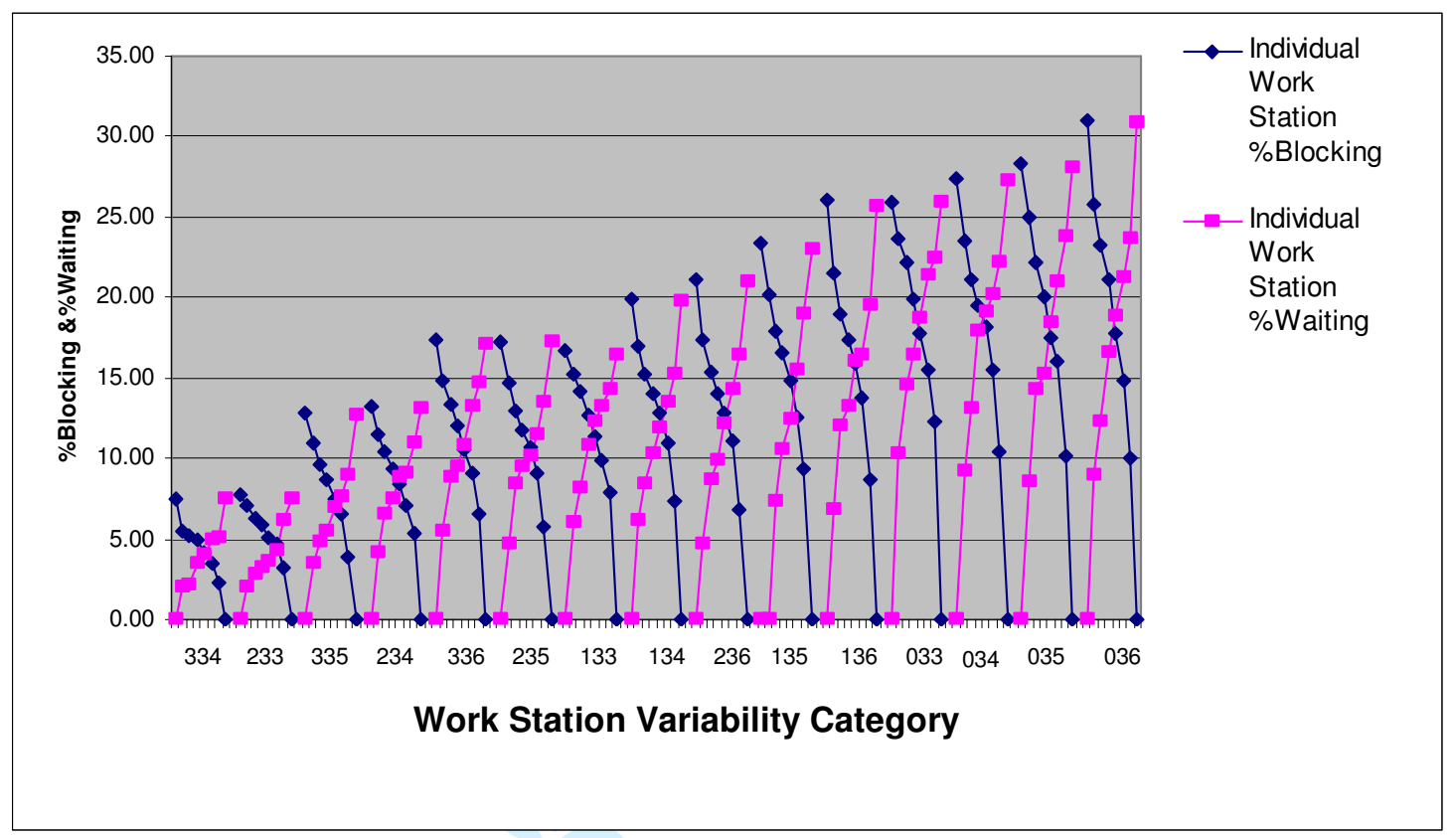

Figure 8: \% Blocking and \% Waiting on 13 Workstation Flow Lines 


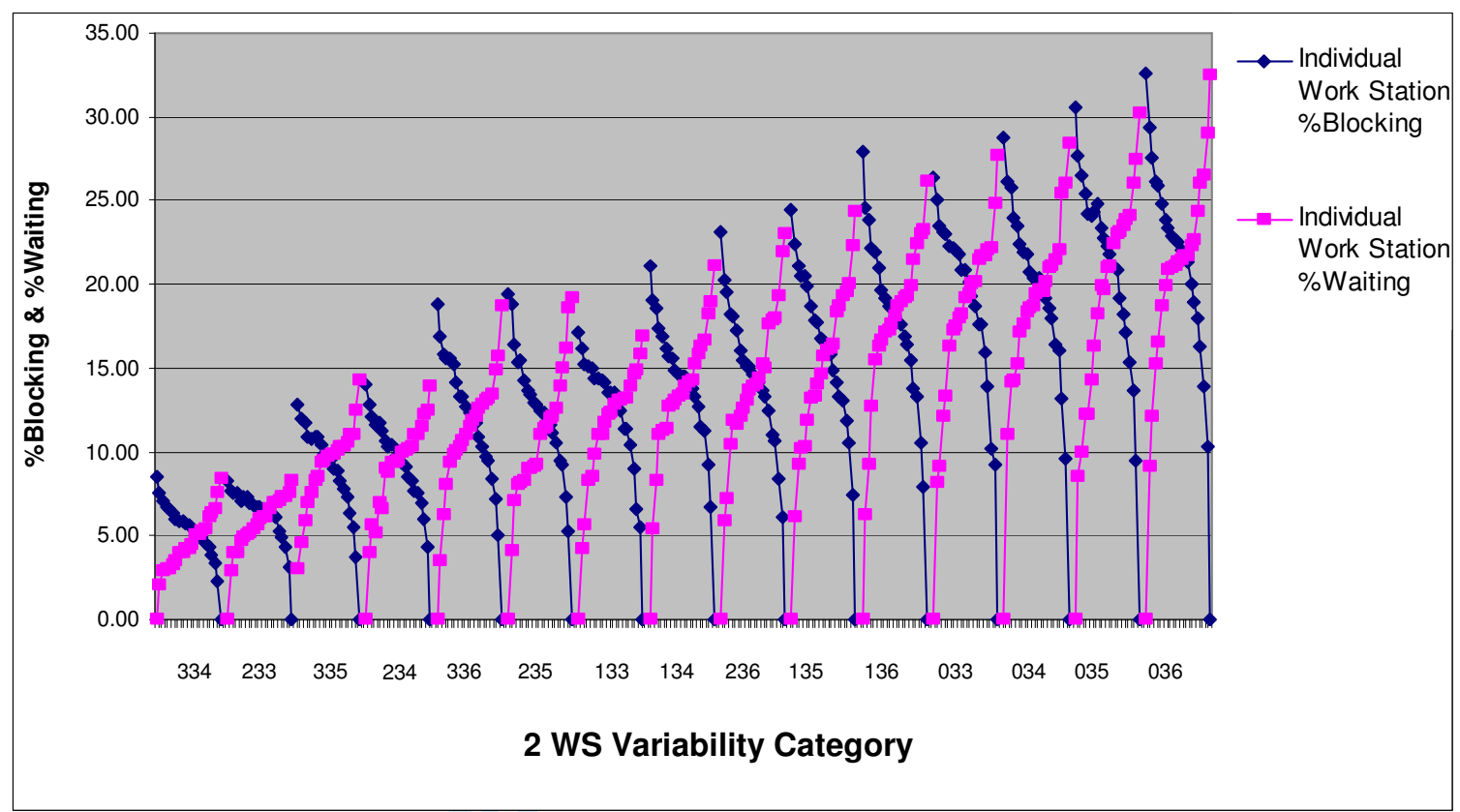

Figure 9: \% Blocking and \% Waiting on 21 Workstation Flow Lines 


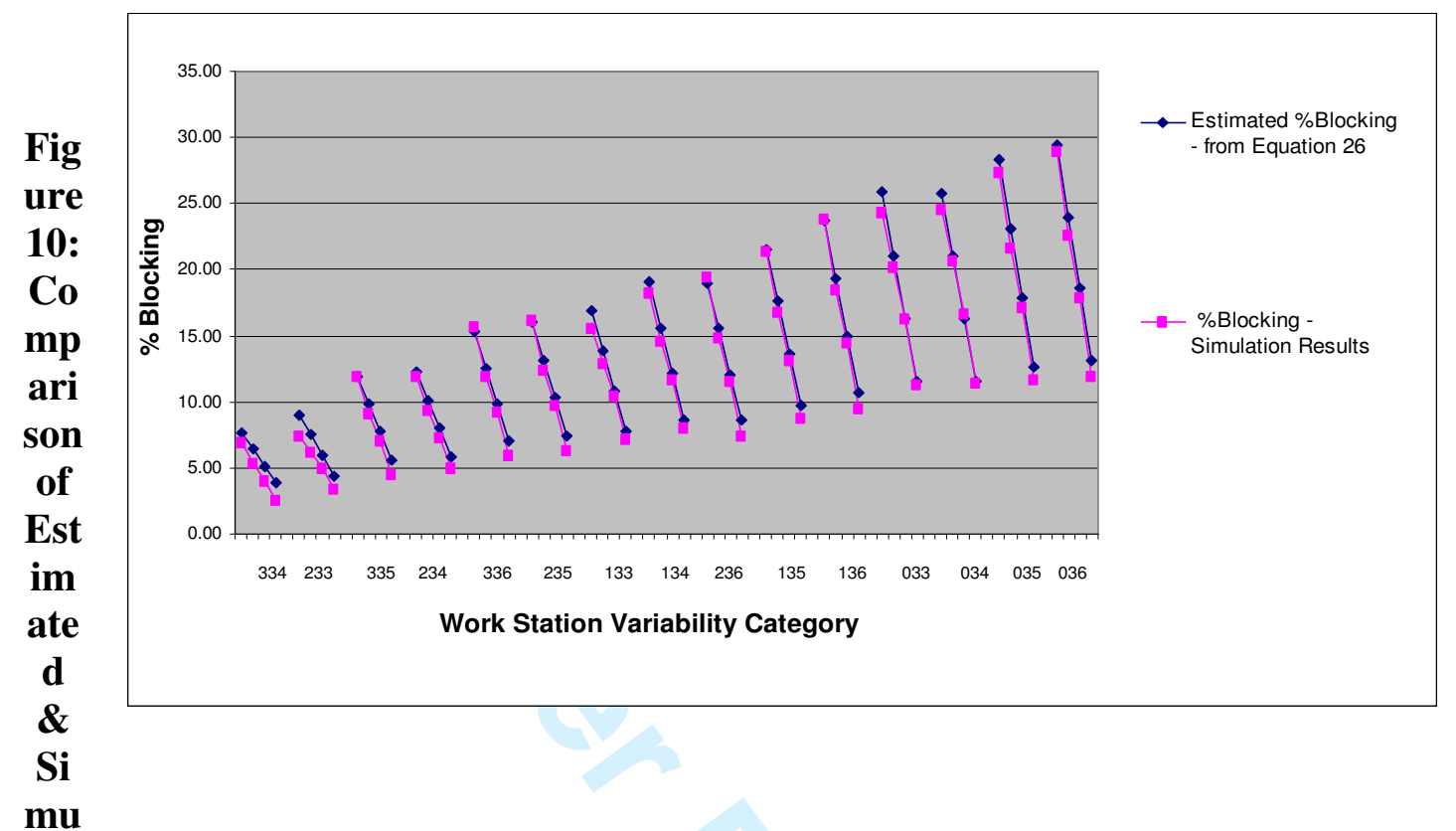

lated \% Blocking

on 5 Workstation Flow Lines: Zero Blocking on $5^{\text {th }}$ Workstation 


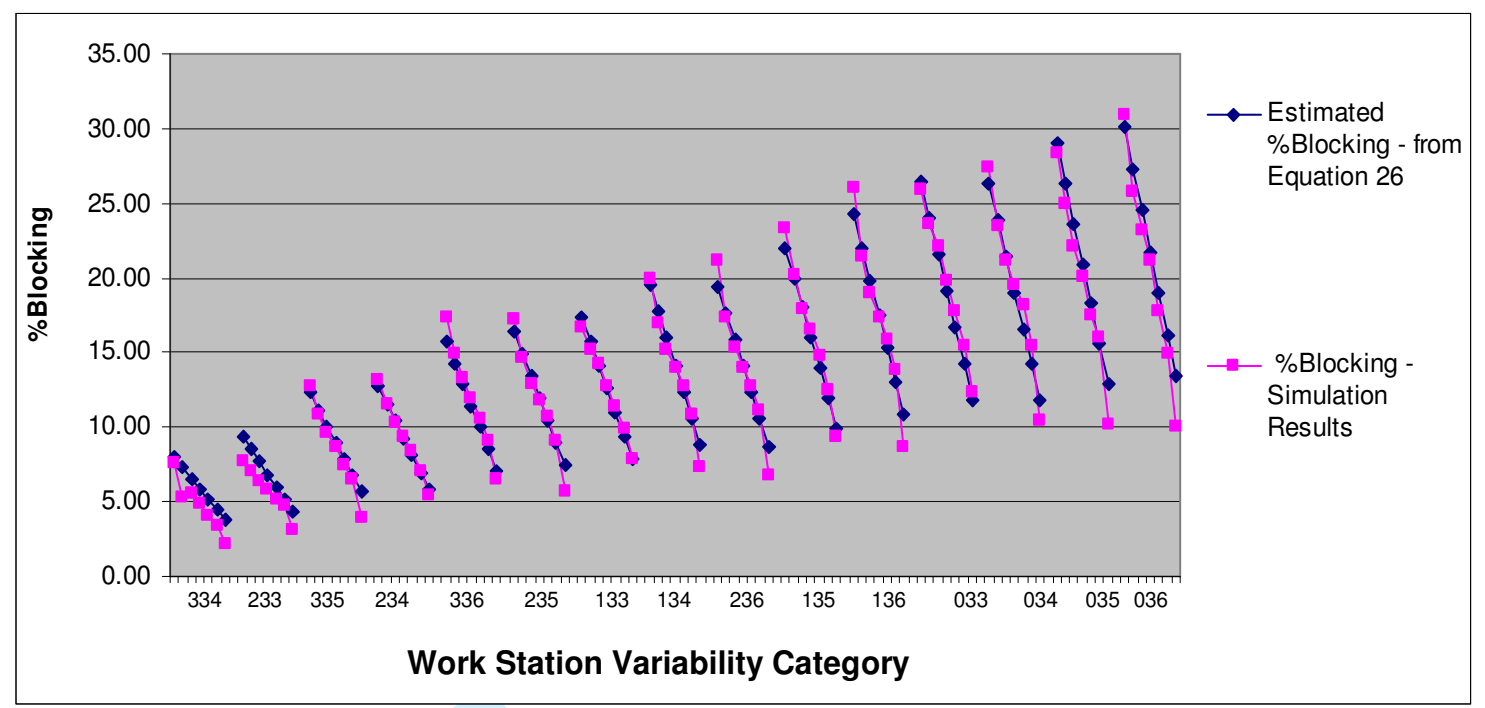

Figure 11: Comparison of Estimated \& Simulated \% Blocking on 8 Workstation Flow Lines: : Zero Blocking on $8^{\text {th }}$ Workstation 


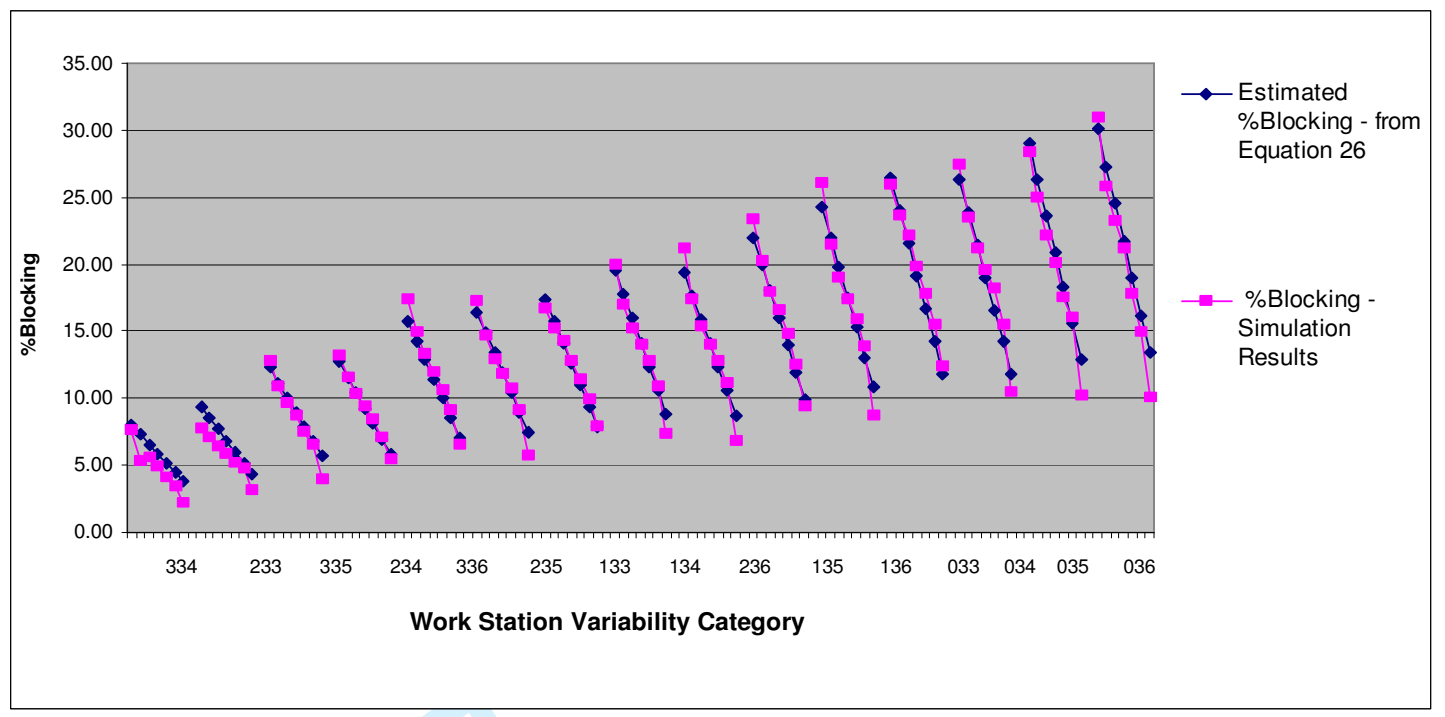

Figure 12: Comparison of Estimated \& Simulated \%Blocking on 3 Workstation Flow Lines : Zero Blocking on $13^{\text {th }}$ Workstation 


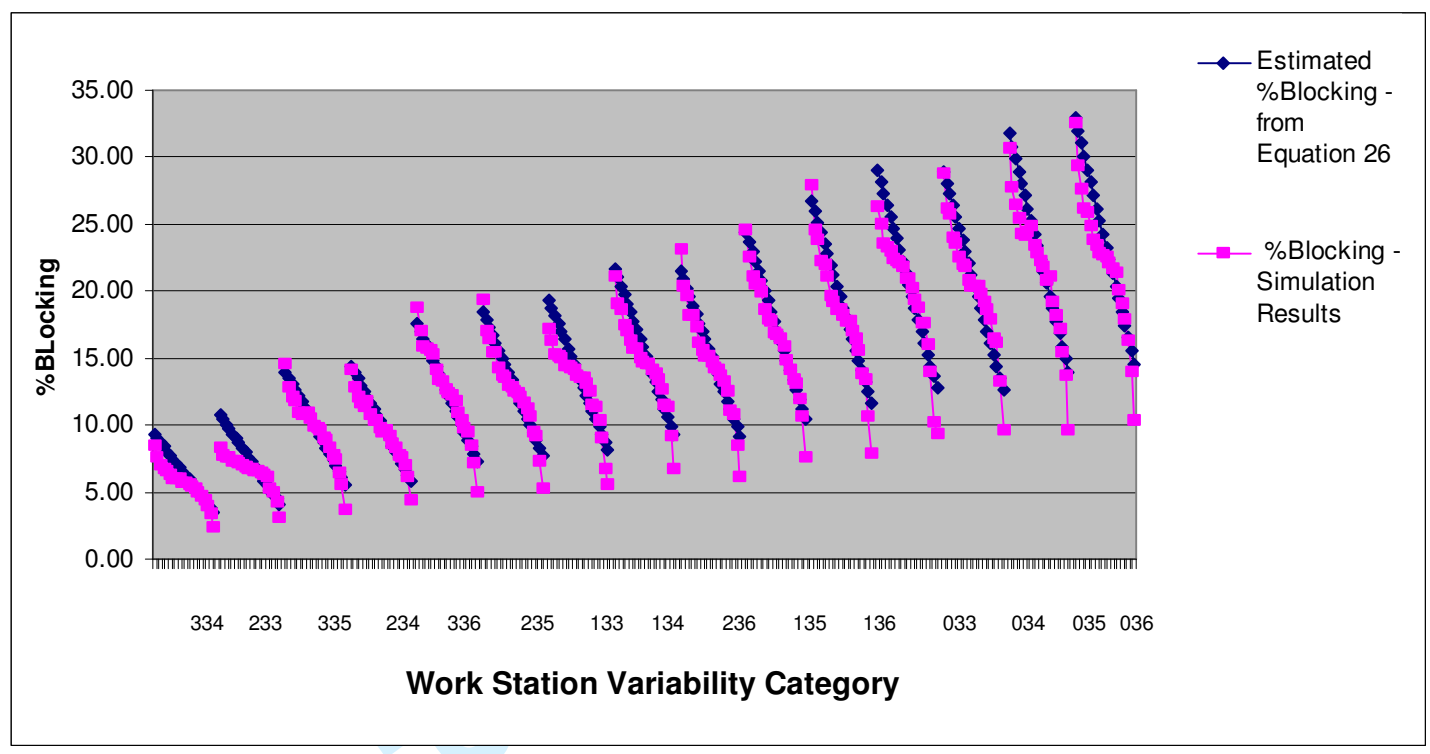

Figure 13: Comparison of Estimated \& Simulated \% Blocking on 21 Workstation Flow Lines: Zero Blocking on $21^{\text {st }}$ Workstation 


\section{LIST OF FIGURE CAPTIONS}

Figure 1: Categories of Probability Distributions

Figure 2: \%Blocking/\%Waiting versus Correlation Coefficient Values

Figure 3: Comparison of Estimated vs. Simulated \%Blocking \& \% Waiting on 2 Workstation (WS) Flow Lines

Figure 4: \% Blocking and \%Waiting on 2 Workstation Flow Lines

Figure 5: \% Blocking and \%Waiting on 3 Workstation Flow Lines

Figure 6: \% Blocking and \%Waiting on 5 Workstation Flow Lines

Figure 7: \% Blocking and \%Waiting on 8 Workstation Flow Lines

Figure 8: \% Blocking and \%Waiting on 13 Workstation Flow Lines

Figure 9: \% Blocking and \%Waiting on 21 Workstation Flow Lines

Figure 10: Comparison of Estimated \& Simulated \%Blocking on 5 Workstation Flow Lines: Zero Blocking on 5th Workstation 
Figure 11: Comparison of Estimated \& Simulated \%Blocking on 8 Workstation Flow Lines: Zero Blocking on 8th Workstation

Figure 12: Comparison of Estimated \& Simulated \%Blocking on 3 Workstation Flow Lines: Zero Blocking on 13th Workstation

Figure 13: Comparison of Estimated \& Simulated \%Blocking on 21 Workstation Flow Lines: Zero Blocking on 21st Workstation 


\section{LIST OF TABLE CAPTIONS}

Table 1: Correlation Coefficient Values for Statistical measures with \%Blocking \& $\%$ Waiting on 2 Workstation Flow Lines

Table 2: Correlation Matrix for Statistical Characteristics 
URL: http://mc.manuscriptcentral.com/tandf/tcim Email:ijcim@bath.ac.uk 